\title{
The Pathogenesis of Lyme Neuroborreliosis: From Infection to Inflammation
}

\author{
Tobias A Rupprecht, ${ }^{1}$ Uwe Koedel, ${ }^{1}$ Volker Fingerle, ${ }^{2}$ and Hans-Walter Pfister ${ }^{1}$ \\ Departments of ${ }^{1}$ Neurology and ${ }^{2}$ Microbiology, Ludwig-Maximilians University, Munich, Germany
}

\begin{abstract}
This review describes the current knowledge of the pathogenesis of acute Lyme neuroborreliosis (LNB), from invasion to inflammation of the central nervous system. Borrelia burgdorferi (B.b.) enters the host through a tick bite on the skin and may disseminate from there to secondary organs, including the central nervous system. To achieve this, B.b. first has to evade the hostile immune system. In a second step, the borrelia have to reach the central nervous system and cross the blood-brain barrier. Once in the cerebrospinal fluid (CSF), the spirochetes elicit an inflammatory response. We describe current knowledge about the infiltration of leukocytes into the CSF in LNB. In the final section, we discuss the mechanisms by which the spirochetal infection leads to the observed neural dysfunction. To conclude, we construct a stringent concept of the pathogenesis of LNB.
\end{abstract}

Online address: http://www.molmed.org

doi: 10.2119/2007-00091.Rupprecht

\section{INTRODUCTION}

Lyme borreliosis is the most common human tick-borne disease in the Northern hemisphere. Its prevalence is estimated to range between 20 and 100 cases per 100,000 people in the US and about 100 to 130 cases per 100,000 in Europe $(1,2)$. It is caused by the spirochete Borrelia burgdorferi (B.b.) sensu lato. B.b. can be divided into four human pathogenic species: B.b. sensu stricto (the only human pathogenic species present in the US), B. afzelii, B. garinii, and B. spielmanii (3).

The infection by B.b. is a complex process beginning with the translation from the gut to the salivary glands of the tick during the feeding process on the host. After invasion into the skin, B.b. can cause a local infection called erythema migrans (EM). During the second stage of Lyme disease, B.b. can spread from the tick bite on the skin to various secondary organs throughout the body, including heart, joints, and peripheral and central nervous system (CNS) (4). Major clinical findings of the neurological manifestation of acute Lyme neuroborreliosis (LNB) include painful meningoradiculitis with inflammation of the nerve roots and lancinating, radicular pain (Bannwarth's syndrome), lymphocytic meningitis, and various forms of cranial or peripheral neuritis (5).

The clinical picture of painful meningoradiculitis was first described in 1922 (6), but the etiology was unknown till the description of the causative spirochetes by Burgdorfer et al. in 1982 (7) and the isolation of spirochetes from the CSF of a patient with Bannwarth's syndrome in 1984 (8). During the last 25 years, we have gained some insight into the pathogenesis of LNB, but there are still many aspects that have not yet been clarified. One reason for our incomplete understanding of the mechanisms that lead to LNB is the limited availability of an adequate animal model. The only induction of reliable, clinically manifest LNB in an animal model so far was in a primate model involving the rhesus macaque, where for example, spirochetes could be demonstrated at the nerve roots (9). Further insight has been gained either from human material or cell culture experiments: whereas, for example, the inflammatory response of the human host to B.b. has been measured in CSF samples (10-12), the mechanisms of adherence of B.b. to endothelial cells, cytotoxicity on neural cells, or the induction of cytokines was analyzed using primary cells or cell lines in vitro (13-17). Though our knowledge of the pathogenesis is still incomplete, in this review we attempt to construct a stringent concept of the pathogenesis of LNB, from the first encounter of the spirochetes with the hostile immune system inside the tick up to the neuronal dysfunction evoked by B.b. as seen in patients with LNB.

\section{HIDING FROM THE IMMUNE SYSTEM}

Even before entering the host, the spirochete has to evade the hostile immune system. During the first 24 to 48 hours of tick feeding, the borrelia are attached to the tick gut, mediated by the
Address correspondence and reprint requests to Hans-Walter Pfister, Department of Neurology, Klinikum Grosshadern, Ludwig-Maximilians University, Marchioninistr. 15, D-81377 Munich, Germany. Phone: +49 89 7095-3676; Fax: +49 89 7095-6673; E-mail: hans-walter.pfister@med.uni-muenchen.de. Submitted September 24, 2007; Accepted for publication December 10, 2007; Epub (www.molmed.org) ahead of print December 13, 2007. 
interaction of the borrelial outer surface protein A (OspA) with the tick receptor for OspA (TROSPA) (18). While the hostile blood flows into the tick gut, the spirochetes multiply and prepare for dissemination to the salivary glands (19). At that time, the borrelia are already faced with the different components of the mammalian immune system. An impressive example of this is the mechanism of action of OspA vaccination: anti-OspA antibodies from the host are able to kill the borreliae already in the tick gut, thereby preventing infection of the host (20). In parallel, the borrelia are confronted with the hostile complement system. The complement system is a biochemical cascade that not only is potentially cytotoxic, but also opsonizes the pathogen and attracts leukocytes (21). The leukocytes constitute another threat for B.b.: different borrelial surface lipoproteins are recognized by leukocytes, mainly by CD14 and the toll-like receptor 2 (TLR2) of the innate immune system $(17,22-24)$, and it has been shown in vitro that the spirochetes are rapidly taken up by polymorphonuclear cells, monocytes, and macrophages (25-27). Once having entered the host, there are further hazards for B.b., especially when seroconversion has taken place, as mouse and human antibodies against different outer surface proteins (for example OspA or OspC) are borreliacidal in vitro $(28,29)$. However, though the mammalian immune system possesses several means to defend itself against the borrelial invasion, the elimination might be incomplete. Without the application of antibiotics, B.b. might persist in the mammalian host; chronic infections have been reported in the literature $(5,30)$.

But why is it so hard for the immune system to attack the borrelia? The borrelia possess several mechanisms that enable them to escape (Figure 1) including (1) downregulation of immunogenic surface proteins, (2) inactivation of effector mechanisms, or (3) hiding in less accessible compartments like the extracellular matrix. This will be depicted in detail below.

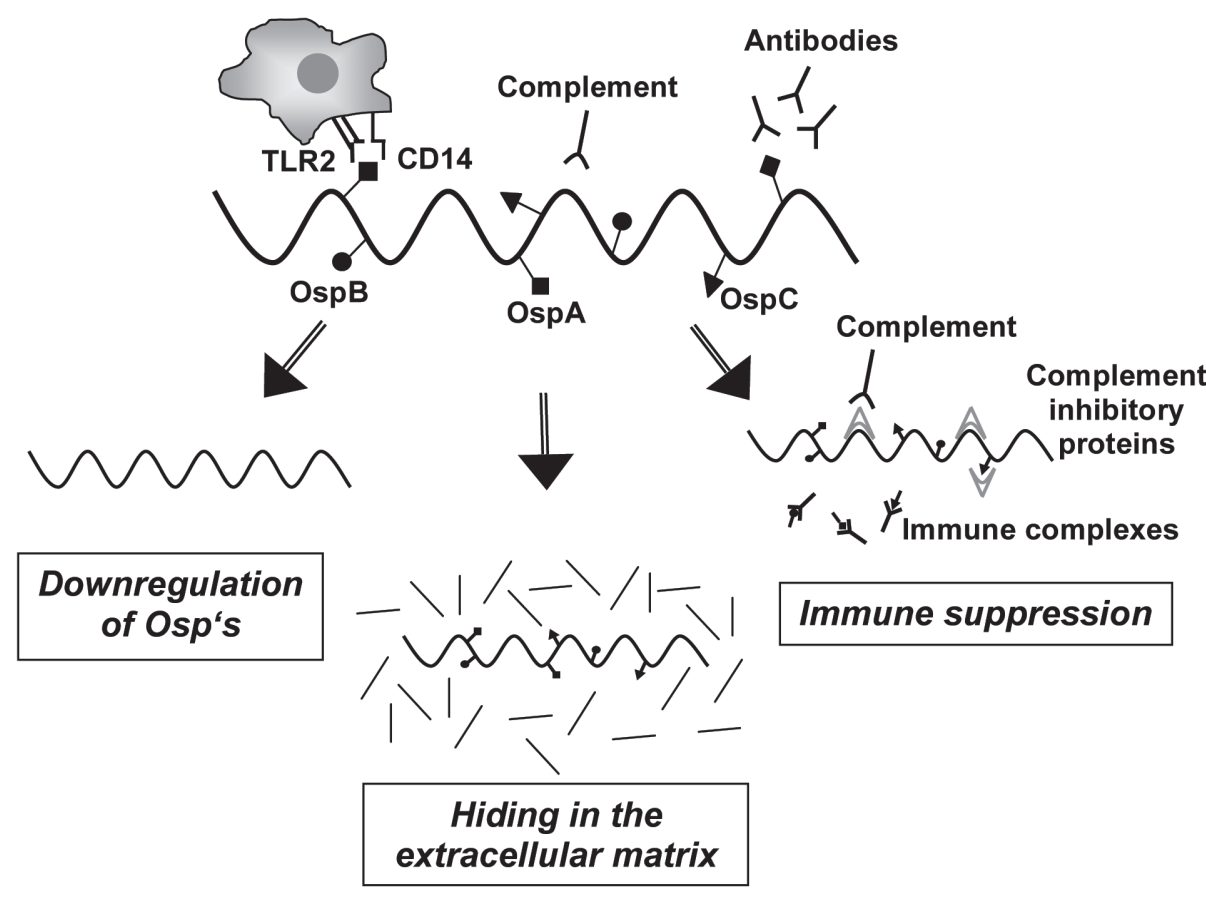

Figure 1. Mechanisms of the borrelia to evade the immune system. Borrelia are recognized by immune cells through TLR2 and CD14 and attacked by complement and antibodies. Therefore, the borrelia downregulate their surface proteins, hide in the extracellular matrix, and use complement-neutralizing proteins like Salp, CRASPs, or ISAC/IRAC or induce the formation of immune complexes by secreting soluble antigens to be protected from recognition and subsequent killing.

\section{Downregulation of Immunogenic Surface Proteins}

To escape from the immune reaction of the host, the borrelia hide highly immunogenic surface proteins using the mechanism of antigenic variation (31). OspA, for example, is a potent stimulator of neutrophils (32) and induces the release of proinflammatory cytokines like interleukin (IL)-1 $\beta$, tumor necrosis factor (TNF)- $\alpha$, or IL-6 in vitro (33). To avoid such an inflammatory response, OspA, while abundantly expressed in the tick gut as an important adhesion protein (34), is rapidly downregulated during the feeding process on the host $(35,36)$. Though OspA-positive borrelia are able to enter the host, they are unable to establish an infection (37), and B.b. isolated from mice four days after infection are all OspA negative (38). It can be concluded from these results that only OspA-negative borrelia are able to survive in the host and therefore, this sur- face protein does not appear to be expressed during the early phase of the infection.

OspC, in contrast, is rapidly upregulated before dissemination to the salivary glands during the blood meal of the tick, most probably mediated by the increasing temperature and the $\mathrm{pH}$ shift as the blood of the host enters the tick gut (39-41). The expression of OspC constitutes an important initial survival factor during transmission from the tick to the host. In a recent study, it was shown that B.b. can bind the complement inhibiting protein Salp15 of the tick saliva via OspC, which protects the spirochete against the hostile complement system (42). Therefore, the expression of OspC appears essential for the first $48 \mathrm{~h}$ of infection to escape the innate immunity (43), and OspC-negative borrelia are unable to disseminate and invade the host. However, a persistent infection of the host is possible by downregulating OspC 
again 8 to 21 days after infection (44). A constitutive expression of OspC - as for example, by a mutation of the respective regulatory element-leads to an efficient clearance of the borrelia once the humoral immune response is set $(44,45)$. Therefore, the borrelia also hide this surface protein later during the course of infection to remain unrecognized from the immune system of the host. This is supported by the finding that anti-OspC antibodies are found in the rhesus monkey up to 20 to 30 days after infection, whereas they disappear in later stages (46). In parallel, neither OspA nor OspC expression can be found in persistent borrelial infection in the rhesus monkey, and the rate of systemic inflammation in these animals is low (47). All in all, it appears that the borrelia suppress or hide several surface markers to minimize their immunogenic characteristics, but a transient expression can be used to utilize protective mechanisms.

\section{Inactivation of Effector Mechanisms}

Besides Salp15, other complementneutralizing substances such as, for example, Salp20, ISAC, or IRAC have been identified in tick saliva (48-50). Therefore, it can be concluded that B.b. uses the immunosuppressive environment as established by the feeding tick to arm itself against the hostile immune system. In addition to these complement-blocking agents supplied by the tick, the borrelia express their own complementbinding proteins on their surface: the complement regulator-acquiring surface proteins (CRASPs) (51), the factor $\mathrm{H}$ binding outer surface protein $\mathrm{E}$ paralogs (52), or the host complement regulatory protein CD59 (protectin) (53). These surface proteins allow the spirochetes to resist complement-mediated killing even inside the host. Another mechanism to impair the hostile immune system is the induction of anti-inflammatory cytokines. IL-10 is considered a key (negative) regulator of inflammatory cytokine release and/or function. It has been shown that B.b. induces the secretion of IL-10 in mononuclear cells (54), and the clearance of $B . b$. in IL-10 deficient mice is 10 times higher than in their wild-type littermates (55). This suggests that borrelia induce IL-10 to inhibit the host defense. Finally, it has been shown that B.b. can release soluble antigens, which aggregate with B.b.-specific antibodies, thus leading to the formation of immune complexes. This might impair the opsonization and, as a consequence, the effective killing of the microbes (56-58). In conclusion, B.b. appears to possess a complex arsenal for an active immune suppression by both downregulating the immune response and neutralizing its effector mechanisms.

\section{Hiding in Less Accessible Compartments}

Finally, invasion of a protected niche can be another way to hide from the hostile immune system as shown so far in vitro. The extracellular matrix is considered one such immunologically privileged site $(59,60)$. It is well known that borrelia can bind plasminogen via OspA on their surface. Although it has been shown in vitro that plasminogen binds to the spirochetal surface very rapidly (starting at $60 \mathrm{~min}$, with a saturation point at $300 \mathrm{~min}$ ), the time course in vivo has not yet been analyzed (61). Plasminogen can be activated to plasmin $(62,63)$, leading to degradation of the extracellular matrix as a prerequisite for its invasion. It is of note, however, that borrelia do not appear to express considerable amounts of OspA during (early) infection $(37,38)$. Therefore, plasminogen might be important for dissemination in the tick, but not in the mammal host (62). OspA-negative borrelia could be using flagellin instead for dissemination. A study using a flagella-less mutant of $B . b$. demonstrated an impaired motility of borrelia lacking flagella. The authors stated that the flagellum and the motility it confers play a role in B.b.'s invasion of human tissue (64).

Furthermore, borrelia lead to a local upregulation of the matrix metalloproteinase-9, which digests the surrounding extracellular matrix (65). In addition, the borrelia can attach to several proteins of the extracellular matrix, such as, for example, fibronectin (66), several integrins (67), or proteoglycans like decorin (68). Decorin is a collagen-binding proteoglycan that is produced as a component of the connective tissue. It facilitates both the dissemination and the survival of Lyme disease spirochetes in decorin-rich tissues (69). As a consequence, the borrelia can hide in these extracellular structures, rendering them less subject to the circulating leukocytes.

\section{INVASION OF THE CENTRAL NERVOUS SYSTEM}

All these well-orchestrated mechanisms may help the borrelia not only to survive, but also, for example by degrading the extracellular matrix, to disseminate in the host (69). There are two alternative ways for the spirochetes to reach the central nervous system from their original point of entry, the skin: either through the bloodstream or along other structures like the peripheral nerves. There are several arguments that favor a dissemination of the spirochetes predominantly by the blood vessel route. First of all, the bloodstream is a well-known route of dissemination for many bacteria in the host and it is therefore likely that B.b. also uses this path. In accordance with this, borrelia can be cultivated in up to $35 \%$ to $45 \%$ of plasma samples from patients with early Lyme disease in the US $(70,71)$. It has to be kept in mind that the effective prevalence of borrelia in the blood of patients will be even higher, as the sensitivity of culture methods can never achieve $100 \%$. Therefore, hematogenous dissemination of the spirochetes can be considered frequent in patients with Lyme disease in the US (71). The exact mechanisms by which the spirochetes travel through and along with the blood and escape the circulating immune cells are not known. Though it would be tempting to speculate that they bind to the integrins on the surface of circulating platelets, it is rather unlikely that spirochetes can use them as a sort of protected transport vehicle, as activated 
platelets are not abundant in the circulation (72). After they have arrived at the cerebral or spinal vessels, the borrelia might attach to the endothelial cells by inducing adhesive proteins like E-selectin, ICAM-1, or VCAM-1 (73), or they can bind via integrins (67) to a localized aggregation of activated platelets (72). One of the borrelial proteins that could be involved in this adhesion process is, as in the tick gut, OspA: antibodies against this surface protein could significantly reduce the adherence to endothelial cells in vitro (13). However, it has to be kept in mind that OspA was found to be downregulated during dissemination in the host $(37,38)$, and therefore, the relevance of this in vitro finding for the in vivo situation would have to be clarified in further studies.

It is still a matter of debate how the borrelia passes the blood-brain barrier. Some authors argue for a penetration of the spirochetes between the endothelial cells $(74,75)$, whereas others favor a transcellular passage (76). Even though the exact mechanism is not yet clarified in detail, the definite entry of borrelia into the cerebrospinal fluid has been documented by both culture methods and PCR $(3,8)$.

In brief, the mechanism of hematogenous dissemination appears to be a suitable way for the spirochetes to enter the central nervous system. Nevertheless, it is of note that the initial and maximal radicular involvement in patients with meningoradiculitis (Bannwarth's syndrome) is often linked to the location of the previous tick bite or the EM-a phenomenon that was observed even years before the spirochetal etiology of Bannwarth's syndrome was known (77). In their report, the authors proposed that the (at that time unknown) microbe would migrate along the peripheral nerves or lymphatic vessels to the central nervous system. This hypothesis is further supported by the fact that a borrelial-induced chemokine, CXCL13 (as described later in detail), can be found in high concentrations in the CSF, but not in the serum, of LNB patients in Europe
$(10,17)$. It could be argued that immune evasion of borrelia by both temporal and spatial regulation of outer surface proteins or binding of immunoinhibitory proteins to its surface during hematogenous dissemination as described above would suppress the immune response and consequently the production of CXCL13 in the serum. However, the prominent induction of CXCL13 in the CSF is not well explained by this theory. Therefore, one might speculate that, according to the observation of Horstrup and Ackermann (77), migration of borrelia along structures other than the blood to the CNS with less contact to the systemic circulation might be the reason for the low blood but high CSF CXCL13 levels in LNB patients. It has to be kept in mind that the most frequent borrelial species isolated from the CSF of patients with Bannwarth's syndrome in Europe is B. garinii. This species has not been detected in the US, where Bannwarth's syndrome is only rarely observed. The most frequent manifestation of LNB in the US is meningitis, caused by B.b. sensu stricto. Therefore, it is tempting to speculate that the process of dissemination in systemic borreliosis is different in Europe and the US. Whereas the meningopolyradiculitis in Bannwarth's syndrome might be the result of a local invasion along the nerves to the nerve roots, the more diffuse meningitis observed in the US could be the result of a hematogenous spread. In this context, it is of note that multiple EM lesions (that can be well explained by hematogenous dissemination) are rather frequent in the US but rare in Europe. In conclusion, dissemination along both the blood vessels or other structures like the peripheral nerves, could be an option for the borrelia to invade the CNS, and the respective mechanism might be due to the distinct borrelial species in Europe and the US.

\section{THE INFLAMMATORY RESPONSE IN THE CNS}

Once they have entered the CNS, the borrelia first encounter local immune cells like monocytes, macrophages, or dendritic cells. On the one hand, these cells produce proinflammatory cytokines like IL-6, IL-8, IL-12, IL-18, or interferon (IFN)- $\gamma$, and increased levels of these cytokines have been found in the CSF of LNB patients (12,78-81). On the other hand, chemokines (chemotactic cytokines) are induced to attract other immune cells to the inflammatory focus. The large family of chemokines, with approximately 50 members known so far, is divided into two major subfamilies, CXC and CC chemokines, based on the arrangement of the first two of four conserved cystein residues $(82,83)$. Besides being grouped on common motifs in their amino acid structure, the chemokines can also be subdivided according to the kind of cells that they predominantly attract. B-lymphocytes, in contrast to other leukocytes, show a substantial migration only in response to very few chemokines, namely the CC chemokines CCL19 and CCL21 and the CXC chemokines CXCL12 and CXCL13 (84). As the leukocyte CSF-infiltrate in neuroborreliosis contains, if compared with other CNS infections, the highest proportion of $\mathrm{B}$ cells $(12,85)$, these chemokines could play an important role in the inflammatory CNS reaction in LNB. One of these chemokines, CXCL13, was found in high concentrations in the CSF of LNB patients (10). It is produced by monocytes (17) and dendritic cells (86) in response to the spirochetal encounter, and both the Pam ${ }_{3}$ Cys motif of the lipoproteins on the borrelial surface and the toll-like receptor TLR2 of the monocytes appear to be involved in the recognition process (Figure 2) (17). Another B-cell-attracting chemokine that has been detected in the CSF of LNB patients is CXCL12 (87). However, the CSF-to-serum ratio of CXCL12 in that study was 1.2, whereas the mean CXCL13 concentration in the CSF of LNB patients was found to be 114 times higher than in the serum. Therefore, it can be argued that the prominent gradient between the high CSF levels and the low serum levels of CXCL13 leads to the invasion of B-lymphocytes into the CSF, but this would have to be 


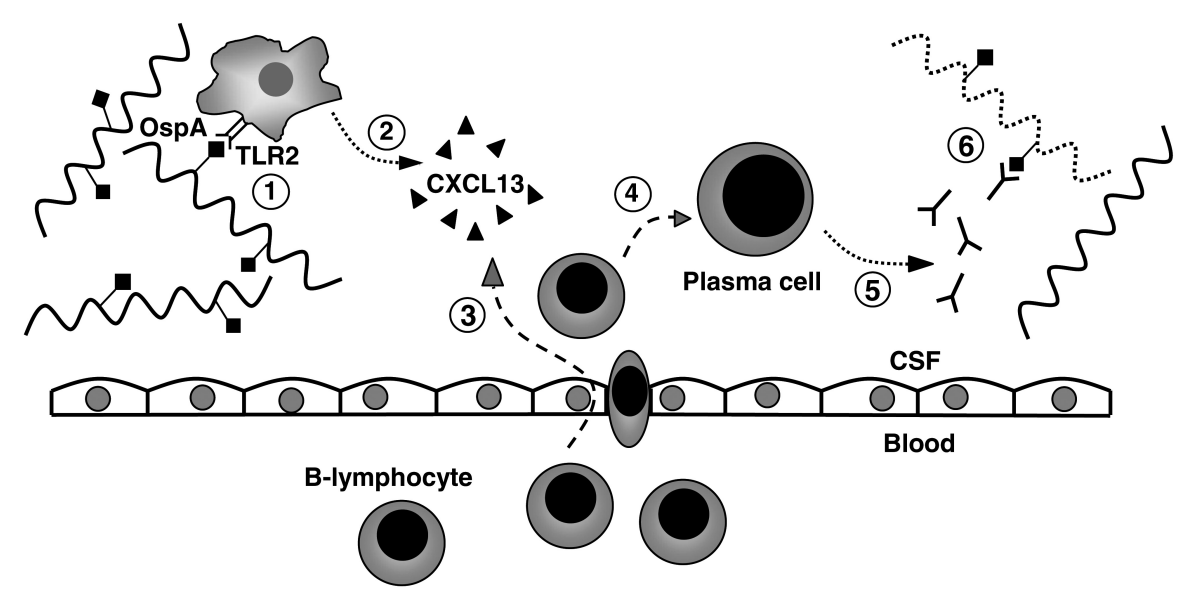

Figure 2. The inflammatory B-cell response in the CSF in response to the CNS infection. Borrelia are recognized by monocytic cells (1), which produce the B-cell-attracting chemokine CXCL13 (2). B cells immigrate into the CSF (3) and mature to plasma cells (4). These plasma cells can produce B.b.-specific antibodies (5) that can eventually destroy the invaded spirochetes (6).

confirmed in migration assays. The lipid moiety of the borrelial OspA is known to induce a polyclonal B-cell activation (88). Subsequently, the B-cells can mature to plasma cells to produce the borreliaspecific antibodies found in the CSF of LNB patients (Figure 2) (3). In accordance with this, elevated CXCL13 concentrations in the CSF can be measured days before intrathecally produced borrelia-specific antibodies appear (89). But how can OspA, though being downregulated during the dissemination process (36), play such an important role in the immune reaction in the CSF? It appears that OspA is upregulated again in the different environment of the CSF, as OspA antigens and antibodies have been detected in the CSF, but not the serum, of LNB patients (90). In addition, it has been shown that OspA expression in vivo can be significantly induced if the spirochetes are kept in an inflammatory environment (91).

Besides B-lymphocytes and plasma cells, there is also a clonal accumulation of activated $\mathrm{CD}^{+} \mathrm{T}$ cells in the CNS during early LNB (92). This lymphocyte subtype could be attracted by the local production of chemokines like CCL4, CCL5, CXCL10, or CXCL11 (82), as increased levels of all these chemokines have been found in the CSF of LNB patients $(87,93,94)$. However, a functional role for the immigration of T-lymphocytes has been shown only for CXCL11 so far (93).

To summarize, the invaded spirochetes are detected by local immune cells, which secret several chemokines that lead to the lymphocytic pleocytosis observed in the CSF of LNB patients. molecular mimicry.

\section{NEURAL DYSFUNCTION IN LNB}

The most prominent clinical manifestation of Bannwarth's syndrome is lancinating radicular pain (5), whereas patients with meningitis suffer mainly from headache and facial nerve palsy $(2,95)$. Besides these symptoms, focal abnormalities like paresis or paresthesias are frequently observed in patients with polyradiculoneuritis or cranial neuritis (5). These symptoms are the result of a focal or diffuse neural dysfunction, but the pathophysiology is far from clear. There are several principal mechanisms that can be considered: direct cytotoxicity, neurotoxic mediators, or triggered autoimmune reactions (Figure 3).

On the one hand, it is well known that borrelia can adhere to murine neural and glial cell lines $(96,97)$, primary neural cells from fetal mice (16), and primary rat brain cultures (96) (Figure 4). This adherence process appears to be mediated by the borrelial OspA (16) and the proteoglycans (16) or the galactocerebrosides (98) on the neural or glial cells. The adherent borrelia can be cytotoxic for the neural cells (97), and OspA induces apoptosis and astrogliosis (99). Therefore, a direct interaction between the borrelia and the neural cells could be responsible for the observed dysfunction.

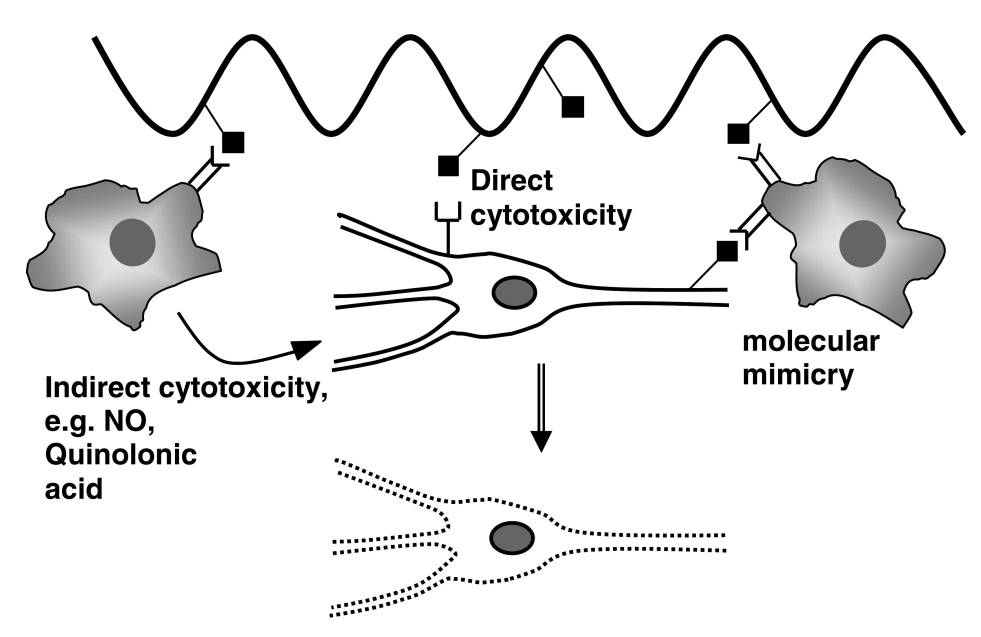

Figure 3. The neural dysfunction in neuroborreliosis. Three principal mechanisms that lead to the injury of neuronal cells: (1) the secretion of cytotoxic substances by leucocytes and glial cells, (2) direct cytotoxicity, and (3) autoimmune-triggered processes through 


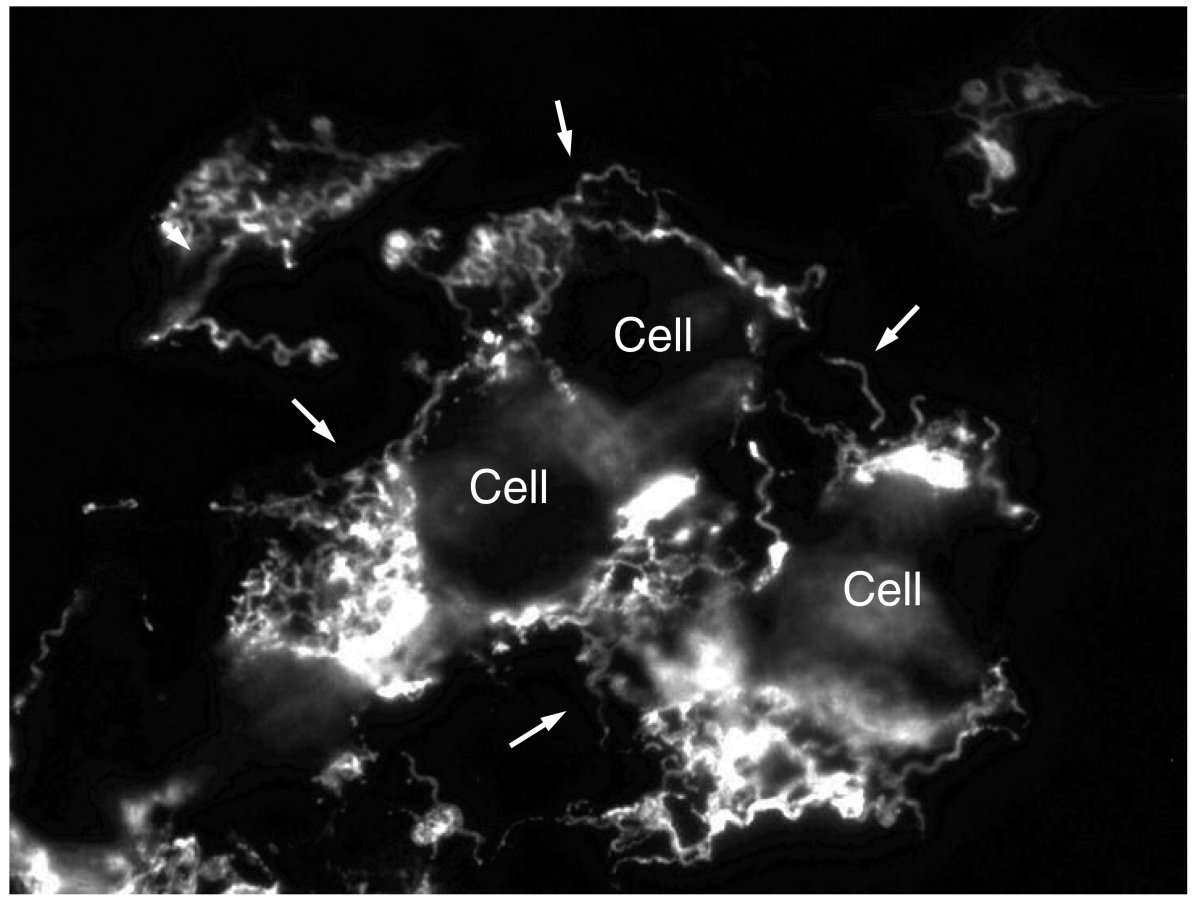

Figure 4. Borrelia adhere to neuronal cells. Borrelia (arrows) are attached to cells of the neuronal cell line B50. The borrelia (B. garinii) were visualized using an OspA monoclonal antibody.

On the other hand, secreted substances could injure the neural cells. Although B.b. do not possess any known endotoxin (100), cells of the host could secret neurotoxic products in response to the spirochetes. Schwann cells, for example, appear to produce nitric oxide (NO) in the rhesus monkey model of LNB (101), and the incubation of glial-enriched primary cultures of neonatal rat brain cells with B.b. leads to the accumulation of $\mathrm{NO}$ in the culture medium (78). In addition, macrophages incubated with B.b. can produce quinolonic acid, an agonist of NMDA synaptic function, which can be neurotoxic in higher concentrations (102). Furthermore, the spirochetes can induce cytokines like IL- 6 or TNF- $\alpha$ in glial cells, both of which are neurotoxic and might provoke autoimmune reactions $(99,103)$. Taken together, the neural dysfunction in LNB patients might also be due to secreted substances that are induced by spirochetes.

Finally, spirochetal-induced, autoimmunemediated mechanisms by "molecular mimicry" could also be an important step in the observed neural dysfunction. Cross-reactive antibodies can be found in Lyme borreliosis (104-106), as the serum of patients with Lyme disease contains antibodies against flagellin of B.b. that cross-react with neural antigens. In this context, it is of note that OspA is also supposed to play a role in autoimmune Lyme arthritis $(30,107)$.

In brief, there are several ways in which borrelia can induce the neuronal dysfunction that leads to the clinical picture of LNB, but further studies would be needed to clarify these yet largely unknown pathophysiological processes.

\section{CONCLUSION}

The pathogenesis of LNB is a complex process with several fascinating aspects, such as, for example, how the borrelia manage to escape the immune system and the ability of the spirochetes to invade the carefully protected CNS. Insights into the pathophysiology of this disease help us to understand the principal microbiological mechanisms involved, and these insights might even be transferable to infections with other spirochetes like Treponema or Leptospira. Therefore, further research on the pathophysiology of infection with B.b. would increase not only the knowledge of Lyme borreliosis but also of other spirochetal diseases, such as syphilis or Weil syndrome, with an increasing incidence and higher morbidity and mortality.

\section{ACKNOWLEDGMENTS}

We thank Katie Ogston and Judy Benson for copyediting the manuscript.

\section{REFERENCES}

1. Huppertz HI, Bohme M, Standaert SM, Karch H Plotkin SA (1999) Incidence of Lyme borreliosis in the Wurzburg region of Germany. Eur. J. Clin. Microbiol. Infect. Dis. 18:697-703.

2. Hengge UR, Tannapfel A, Tyring SK, Erbel R, Arendt G, Ruzicka T (2003) Lyme borreliosis. Lancet Infect. Dis. 3:489-500.

3. Wilske B, Fingerle V, Schulte-Spechtel U (2007) Microbiological and serological diagnosis of Lyme borreliosis. FEMS Immunol. Med. Microbiol. 49:13-21.

4. Pfister HW, Wilske B, Weber K (1994) Lyme borreliosis: basic science and clinical aspects. Lancet 343:1013-6.

5. Pfister HW, Rupprecht TA (2006) Clinical aspects of neuroborreliosis and post-Lyme disease syndrome in adult patients. Int. J. Med. Microbiol. 9:11-6.

6. Garin C, Bujadoux C (1922) Paralysie par les tiques. J. Med. Lyon 71:765-7.

7. Burgdorfer W, Barbour AG, Hayes SF, Benach JL, Grunwaldt E, Davis JP (1982) Lyme disease: a tick-borne spirochetosis? Science 216:1317-9.

8. Pfister HW, Einhaupl K, Preac-Mursic V, Wilske B, Schierz G (1984) The spirochetal etiology of lymphocytic meningoradiculitis of Bannwarth (Bannwarth's syndrome). J. Neurol. 231:141-4.

9. Pachner AR, Gelderblom H, Cadavid D (2001) The rhesus model of Lyme neuroborreliosis. Immunol. Rev. 183:186-204.

10. Rupprecht TA, Pfister HW, Angele B, Kastenbauer S, Wilske B, Koedel U (2005) The chemokine CXCL13 (BLC): a putative diagnostic marker for neuroborreliosis. Neurology 65:448-50.

11. Pachner AR, Amemiya K, Delaney E, O'Neill T, Hughes CA, Zhang WF (1997) Interleukin-6 is expressed at high levels in the CNS in Lyme neuroborreliosis. Neurology 49:147-52.

12. Cepok S, et al. (2003) The immune response at onset and during recovery from Borrelia burgdorferi meningoradiculitis. Arch. Neurol. 60:849-55.

13. Comstock LE, Fikrig E, Shoberg RJ, Flavell RA, 
Thomas DD (1993) A monoclonal antibody to OspA inhibits association of Borrelia burgdorferi with human endothelial cells. Infect. Immun 61:423-31.

14. Thomas DD, Comstock LE (1989) Interaction of Lyme disease spirochetes with cultured eucaryotic cells. Infect. Immun. 57:1324-1326.

15. Garcia-Monco JC, Villar BF, Szczepanski A, Benach JL (1991) Cytotoxicity of Borrelia burgdorferi for cultured rat glial cells. J. Infect. Dis. 163:1362-6.

16. Rupprecht TA, et al. (2006) Adhesion of Borrelia garinii to neuronal cells is mediated by the interaction of OspA with proteoglycans. J. Neuroimmunol. 175:5-11.

17. Rupprecht TA, et al. (2007) Borrelia garinii induces CXCL13 production in human monocytes through TLR2. Infect. Immun. 75:4351-6.

18. Pal U, et al. (2004) TROSPA, an Ixodes scapularis receptor for Borrelia burgdorferi. Cell 119:457-68.

19. de Silva AM, Telford SR III, Brunet LR, Barthold SW, Fikrig E (1996) Borrelia burgdorferi OspA is an arthropod-specific transmission-blocking Lyme disease vaccine. J. Exp. Med. 183:271-5.

20. Fikrig E, Telford SR III, Barthold SW, Kantor FS, Spielman A, Flavell RA (1992) Elimination of Borrelia burgdorferi from vector ticks feeding on OspAimmunized mice. Proc. Natl. Acad. Sci. U. S. A. 89:5418-21.

21. Walport MJ (2001) Complement. First of two parts. N. Engl. J. Med. 344:1058-66.

22. Schroder NW, et al. (2004) Lipopolysaccharide binding protein binds to triacylated and diacylated lipopeptides and mediates innate immune responses. J. Immunol. 173:2683-91.

23. Hirschfeld M, et al. (1999) Cutting edge: inflammatory signaling by Borrelia burgdorferi lipoproteins is mediated by Toll-like receptor 2. J. Immunol. 163:2382-6.

24. Sellati TJ, et al. (1999) Activation of human monocytic cells by Borrelia burgdorferi and Treponema pallidum is facilitated by CD14 and correlates with surface exposure of spirochetal lipoproteins. J. Immunol. 163:2049-56.

25. Montgomery RR, Lusitani D, de Boisfleury CA, Malawista SE (2002) Human phagocytic cells in the early innate immune response to Borrelia burgdorferi. J. Infect. Dis. 185:1773-9.

26. Montgomery RR, Nathanson MH, Malawista SE (1993) The fate of Borrelia burgdorferi, the agent for Lyme disease, in mouse macrophages: destruction, survival, recovery. J. Immunol. 150:909-15.

27. Moore MW, et al. (2007) Phagocytosis of Borrelia burgdorferi and Treponema pallidum potentiates innate immune activation and induces gamma interferon production. Infect. Immun. 75:2046-62.

28. Sadziene A, Barbour A (1996) Experimental immunization against Lyme Borreliosis with recombinant Osp proteins: an overview. Infection 24:195-202.

29. Lovrich SD, Jobe DA, Schell RF, Callister SM (2005) Borreliacidal OspC antibodies specific for a highly conserved epitope are immunodominant in human Lyme disease and do not occur in mice or hamsters. Clin. Diagn. Lab. Immunol. 12:746-51.

30. Steere AC, Glickstein L (2004) Elucidation of Lyme arthritis. Nat. Rev. Immunol. 4:143-52.

31. Norris SJ (2006) Antigenic variation with a twist: the Borrelia story. Mol. Microbiol. 60:1319-22.

32. Morrison TB, Weis JH, Weis JJ (1997) Borrelia burgdorferi outer surface protein A (OspA) activates and primes human neutrophils. J. Immunol. 158:4838-45.

33. Häupl T, et al. (1997) Activation of monocytes by three OspA vaccine candidates: lipoprotein OspA is a potent stimulator of monokines. FEMS Immunol. Med. Microbiol. 19:15-23.

34. Pal U, et al. (2000) Attachment of Borrelia burgdorferi within Ixodes scapularis mediated by outer surface protein A. J. Clin. Invest. 106:561-9.

35. Wilske B, Pfister HW (1995) Lyme borreliosis research. Curr. Opin. Infect. Dis. 8:137-144.

36. Schwan TG, Piesman J (2000) Temporal changes in outer surface proteins A and C of the Lyme disease-associated spirochete, Borrelia burgdorferi, during the chain of infection in ticks and mice. J. Clin. Microbiol. 38:382-8.

37. Ohnishi J, Piesman J, de Silva AM (2001) Antigenic and genetic heterogeneity of Borrelia burgdorferi populations transmitted by ticks. Proc. Natl. Acad. Sci. U. S. A. 98:670-5.

38. Cassatt DR, Patel NK, Ulbrandt ND, Hanson MS (1998) DbpA, but not OspA, is expressed by Borrelia burgdorferi during spirochetemia and is a target for protective antibodies. Infect. Immun. 66:5379-87.

39. Pal U, et al. (2004) OspC facilitates Borrelia burgdorferi invasion of Ixodes scapularis salivary glands. J. Clin. Invest. 113:220-30.

40. Fingerle V, Goettner G, Gern L, Wilske B, SchulteSpechtel U (2007) Complementation of a Borrelia afzelii OspC mutant highlights the crucial role of OspC for dissemination of Borrelia afzelii in Ixodes ricinus. Int. J. Med. Microbiol. 297:97-107.

41. Schwan TG, Piesman J, Golde WT, Dolan MC, Rosa PA (1995) Induction of an outer surface protein on Borrelia burgdorferi during tick feeding. Proc. Natl. Acad. Sci. U. S. A. 92:2909-13.

42. Ramamoorthi N, et al. (2005) The Lyme disease agent exploits a tick protein to infect the mammalian host. Nature 436:573-7.

43. Gilbert MA, Morton EA, Bundle SF, Samuels DS (2007) Artificial regulation of ospC expression in Borrelia burgdorferi. Mol. Microbiol. 63:1259-73.

44. Tilly K, Bestor A, Jewett MW, Rosa P (2007) Rapid clearance of Lyme disease spirochetes lacking OspC from skin. Infect. Immun. 75:1517-9.

45. Xu Q, Seemanapalli SV, McShan K, Liang FT (2006) Constitutive expression of outer surface protein $\mathrm{C}$ diminishes the ability of Borrelia burgdorferi to evade specific humoral immunity. Infect. Immun. 74:5177-84.

46. Pachner AR, et al. (2002) Humoral immune response associated with Lyme borreliosis in nonhuman primates: analysis by immunoblotting and enzyme-linked immunosorbent assay with sonicates or recombinant proteins. Clin. Diagn. Lab. Immunol. 9:1348-55.

47. Cadavid D, O'Neill T, Schaefer H, Pachner AR (2000) Localization of Borrelia burgdorferi in the nervous system and other organs in a nonhuman primate model of Lyme disease. Lab. Invest. 80:1043-54.

48. Tyson K, Elkins C, Patterson H, Fikrig E, de Silva A (2007) Biochemical and functional characterization of Salp20, an Ixodes scapularis tick salivary protein that inhibits the complement pathway. Insect Mol. Biol. 16:469-79.

49. Valenzuela JG, Charlab R, Mather TN, Ribeiro JM (2000) Purification, cloning, and expression of a novel salivary anticomplement protein from the tick, Ixodes scapularis. J. Biol. Chem. 275:18717-23.

50. Daix V, et al. (2007) Ixodes ticks belonging to the Ixodes ricinus complex encode a family of anticomplement proteins. Insect Mol. Biol. 16:155-66.

51. Kraiczy P, Skerka C, Kirschfink M, Zipfel PF, Brade V (2002) Immune evasion of Borrelia burgdorferi: insufficient killing of the pathogens by complement and antibody. Int. J. Med. Microbiol. 291 Suppl 33:141-6.

52. Alitalo A, et al. (2002) Complement inhibitor factor $\mathrm{H}$ binding to Lyme disease spirochetes is mediated by inducible expression of multiple plasmid-encoded outer surface protein E paralogs. J. Immunol. 169:3847-53.

53. Pausa M, et al. (2003) Serum-resistant strains of Borrelia burgdorferi evade complement-mediated killing by expressing a CD59-like complement inhibitory molecule. J. Immunol. 170:3214-22.

54. Giambartolomei GH, Dennis VA, Philipp MT (1998) Borrelia burgdorferi stimulates the production of interleukin-10 in peripheral blood mononuclear cells from uninfected humans and rhesus monkeys. Infect. Immun. 66:2691-7.

55. Lazarus JJ, Meadows MJ, Lintner RE, Wooten RM (2006) IL-10 deficiency promotes increased Borrelia burgdorferi clearance predominantly through enhanced innate immune responses. J. Immunol. 177:7076-85.

56. Embers ME, Ramamoorthy R, Philipp MT (2004) Survival strategies of Borrelia burgdorferi, the etiologic agent of Lyme disease. Microbes Infect. 6:312-8.

57. Schutzer SE, Coyle PK, Reid P, Holland B (1999) Borrelia burgdorferi-specific immune complexes in acute Lyme disease. JAMA 282:1942-6.

58. Coyle PK, Schutzer SE, Belman AL, Krupp LB Golightly MG (1990) Cerebrospinal fluid immune complexes in patients exposed to Borrelia burgdorferi: detection of Borrelia-specific and -nonspecific complexes. Ann. Neurol. 28:739-44.

59. Liang FT, Brown EL, Wang T, Iozzo RV, Fikrig E (2004) Protective niche for Borrelia burgdorferi to evade humoral immunity. Am. J. Pathol. 165:977-85.

60. Cabello FC, Godfrey HP, Newman SA (2007) Hidden in plain sight: Borrelia burgdorferi and the extracellular matrix. Trends Microbiol. 15:350-4.

61. Fuchs H, Wallich R, Simon MM, Kramer MD (1994) The outer surface protein A of the spirochete Borrelia burgdorferi is a plasmin(ogen) receptor. Proc. Natl. Acad. Sci. U. S. A. 91:12594-8. 
62. Coleman JL, Gebbia JA, Piesman J, Degen JL, Bugge TH, Benach JL (1997) Plasminogen is required for efficient dissemination of B. burgdorferi in ticks and for enhancement of spirochetemia in mice. Cell 89:1111-9.

63. Coleman JL, Roemer EJ, Benach JL (1999) Plasmincoated Borrelia burgdorferi degrades soluble and insoluble components of the mammalian extracellular matrix. Infect. Immun. 67:3929-36.

64. Sadziene A, Thomas DD, Bundoc VG, Holt SC, Barbour AG (1991) A flagella-less mutant of Borrelia burgdorferi: structural, molecular, and in vitro functional characterization. J. Clin. Invest. 88:82-92.

65. Zhao Z, Chang H, Trevino RP, Whren K, Bhawan J, Klempner MS (2003) Selective up-regulation of matrix metalloproteinase- 9 expression in human erythema migrans skin lesions of acute Lyme disease. J. Infect. Dis. 188:1098-104.

66. Fischer JR, LeBlanc KT, Leong JM (2006) Fibronectin binding protein BBK32 of the Lyme disease spirochete promotes bacterial attachment to glycosaminoglycans. Infect. Immun. 74:435-41.

67. Coburn J, Magoun L, Bodary SC, Leong JM (1998) Integrins $\alpha v \beta 3$ and $\alpha 5 \beta 1$ mediate attachment of Lyme disease spirochetes to human cells. Infect. Immun. 66:1946-52.

68. Guo BP, Norris SJ, Rosenberg LC, Hook M (1995) Adherence of Borrelia burgdorferi to the proteoglycan decorin. Infect. Immun. 63:3467-72.

69. Coburn J, Fischer JR, Leong JM (2005) Solving a sticky problem: new genetic approaches to host cell adhesion by the Lyme disease spirochete. Mol. Microbiol. 57:1182-1195.

70. Coulter P, et al. (2005) Two-year evaluation of Borrelia burgdorferi culture and supplemental tests for definitive diagnosis of Lyme disease. J. Clin. Microbiol. 43:5080-4.

71. Wormser GP, McKenna D, Carlin J, et al. (2005) Brief communication: hematogenous dissemination in early Lyme disease. Ann. Intern. Med. 142:751-5.

72. Coburn J, Leong JM, Erban JK (1993) Integrin alpha Ilb beta 3 mediates binding of the Lyme disease agent Borrelia burgdorferi to human platelets. Proc. Natl. Acad. Sci. U. S. A. 90:7059-63.

73. Ebnet K, Brown KD, Siebenlist UK, Simon MM, Shaw S (1997) Borrelia burgdorferi activates nuclear factor- $\kappa \mathrm{B}$ and is a potent inducer of chemokine and adhesion molecule gene expression in endothelial cells and fibroblasts. J. Immunol. 158:3285-92.

74. Grab DJ, et al. (2005) Borrelia burgdorferi, host-derived proteases, and the blood-brain barrier. Infect. Immun. 73:1014-22.

75. Szczepanski A, Furie MB, Benach JL, Lane BP, Fleit HB (1990) Interaction between Borrelia burgdorferi and endothelium in vitro. J. Clin. Invest. 85:1637-47.

76. Comstock LE, Thomas DD (1989) Penetration of endothelial cell monolayers by Borrelia burgdorferi. Infect. Immun. 57:1626-8.

77. Horstrup P, Ackermann R (1973) [Tick born meningopolyneuritis (Garin-Bujadoux, Bann- warth) (author's transl)]. Fortschr. Neurol. Psychiatr. Grenzgeb. 41:583-606.

78. Tatro J, Romero L, Beasley D, Steere A, Reichlin S (1994) Borrelia burgdorferi and Escherichia coli lipopolysaccharides induce nitric oxide and interleukin-6 production in cultured rat brain cells. J. Infect. Dis. 169:1014-22.

79. Grusell M, Widhe M, Ekerfelt C (2002) Increased expression of the Th1-inducing cytokines interleukin-12 and interleukin-18 in cerebrospinal fluid but not in sera from patients with Lyme neuroborreliosis. J. Neuroimmunol. 131:173-8.

80. Widhe M, et al. (2004) Borrelia-specific interferongamma and interleukin-4 secretion in cerebrospinal fluid and blood during Lyme borreliosis in humans: association with clinical outcome. J. Infect. Dis. 189:1881-91.

81. Weller M, Stevens A, Sommer N, Wiethölter H, Dichgans J. (1991) Cerebrospinal fluid interleukins, immunoglobulins, and fibronectin in neuroborreliosis. Arch. Neurol. 48:837-41.

82. Baggiolini M (1998) Chemokines and leukocyte traffic. Nature 392:565-8.

83. Lahrtz F, Piali L, Spanaus KS, Seebach J, Fontana A (1998) Chemokines and chemotaxis of leukocytes in infectious meningitis. J. Neuroimmunol. 85:33-43.

84. Brandes M, Legler DF, Spoerri B, Schaerli P, Moser B (2000) Activation-dependent modulation of B lymphocyte migration to chemokines. Int. Immunol. 12:1285-92.

85. Cepok S, et al. (2005) Short-lived plasma blasts are the main B cell effector subset during the course of multiple sclerosis. Brain 128(Pt 7):1667-76.

86. Narayan K, et al. (2005) The nervous system as ectopic germinal center: CXCL13 and IgG in Lyme neuroborreliosis. Ann. Neurol. 57:813-23.

87. Pashenkov M, et al. (2002) Recruitment of dendritic cells to the cerebrospinal fluid in bacterial neuroinfections. J. Neuroimmunol. 122:106-16.

88. Weis JJ, Ma Y, Erdile LF (1994) Biological activities of native and recombinant Borrelia burgdorferi outer surface protein A: dependence on lipid modification. Infect. Immun. 62:4632-6.

89. Rupprecht TA, Koedel U, Angele B, Fingerle V, Pfister HW (2006) [Cytokine CXCL13: a possible early CSF marker for neuroborreliosis.]. Nervenarzt. 77:470-3.

90. Schutzer SE, et al. (1997) Simultaneous expression of Borrelia OspA and OspC and IgM response in cerebrospinal fluid in early neurologic Lyme disease. J. Clin. Invest. 100:763-7.

91. Crowley H, Huber BT (2003) Host-adapted Borrelia burgdorferi in mice expresses OspA during inflammation. Infect. Immun. 71:4003-10.

92. Jacobsen M, et al. (2003) Clonal accumulation of activated $\mathrm{CD}^{+} \mathrm{T}$ cells in the central nervous system during the early phase of neuroborreliosis. J. Infect. Dis. 187:963-73.

93. Rupprecht TA, Koedel U, Muhlberger B, Wilske B, Fontana A, Pfister HW (2005) CXCL11 is involved in leucocyte recruitment to the central nervous system in neuroborreliosis. J. Neurol. 252:820-3.
94. Lepej SZ, Rode OD, Jeren T, Vince A, Remenar A, Barsic B (2005) Increased expression of CXCR3 and CCR5 on memory CD4 ${ }^{+}$T-cells migrating into the cerebrospinal fluid of patients with neuroborreliosis: the role of CXCL10 and CXCL11. J. Neuroimmunol. 163:128-34.

95. Pachner AR, Steiner I (2007) Lyme neuroborreliosis: infection, immunity, and inflammation. Lancet Neurol. 6:544-52.

96. Garcia-Monco J, Fernandez-Villar B, Benach J (1989) Adherence of the Lyme disease spirochete to glial cells and cells of glial origin. J. Infect. Dis. 160:497-506.

97. Peters DJ, Benach JL (1997) Borrelia burgdorferi adherence and injury to undifferentiated and differentiated neural cells in vitro. J. Infect. Dis. 176:470-7.

98. Garcia-Monco JC, Fernandez-Villar B, Rogers RC, Szczepanski A, Wheeler CM, Benach JL (1992) Borrelia burgdorferi and other related spirochetes bind to galactocerebroside. Neurology 42:1341-8.

99. Ramesh G, et al. (2003) Pathogenesis of Lyme neuroborreliosis: Borrelia burgdorferi lipoproteins induce both proliferation and apoptosis in rhesus monkey astrocytes. Eur. J. Immunol. 33:2539-50.

100. Norgard M, Arndt L, Akins D, Curetty L, Harrich D, Radolf J (1996) Activation of human monocytic cells by Treponema pallidum and Borrelia burgdorferi lipoproteins and synthetic lipopeptides proceeds via a pathway distinct from that of lipopolysaccharide but involves the transcriptional activator NF-kB. Infect. Immun. 64:3845-52.

101. Roberts ED, et al. (1998) Pathogenesis of Lyme neuroborreliosis in the Rhesus monkey: the early disseminated and chronic phases of disease in the peripheral nervous system. J. Infect. Dis. 178:722-32

102. Halperin JJ, Heyes MP (1992) Neuroactive kynurenines in Lyme borreliosis. Neurology 42:43-50.

103. Habicht GS, Katona LI, Benach JL (1991) Cytokines and the pathogenesis of neuroborreliosis: Borrelia burgdorferi induces glioma cells to secrete interleukin-6. J. Infect. Dis. 164:568-74.

104. Alaedini A, Latov N (2005) Antibodies against OspA epitopes of Borrelia burgdorferi cross-react with neural tissue. J. Neuroimmunol. 159:192-5.

105. Sigal LG, Tatum AH (1988) Lyme disease patients' serum contains IgM antibodies to Borrelia burgdorferi that cross-react with neuronal antigens. Neurology 38:1439-42.

106. Sigal LH (1993) Cross-reactivity between Borrelia burgdorferi Flagellin and a human axonal 64.000 molecular weight protein. J. Infect. Dis. 167:1372-8.

107. Lengl-Janßen B, Strauss A, Steere AC, Kamradt T (1994) The T helper cell response in Lyme arthritis: differential recognition of Borrelia burgdorferi outer surface protein A in patients with treatment-resistant or treatment-responsive Lyme arthritis. J. Exp. Med. 180:2069-78. 